\title{
PROMETEO Y LAS DOS ALFORJAS. \\ BREVE COMENTARIO HISTORIOGRÁFICO EN TORNO A \\ LOS ESTUDIOS SOBRE LOS ORÍGENES DEL PERONISMO
}

RUBÉN CORREA

Universidad Nacional de Salta

A la memoria de Dario Macor, maestro al cual

siempre recordaremos con afecto y agradecimiento.

«Dejo mis viejos libros, recogidos

en rincones del mundo, venerados

en su tipografía majestuosa,

a los nuevos poetas de América,

a los que un día

hilarán en el ronco telar interrumpido

las significaciones de mañana.»

Pablo Neruda, Testamento (II)

\section{Interpretaciones en disputa}

Pasaron diez años desde la presentación del volumen I de La invención del peronismo en el interior del país, editado por Darío Macor y César Tcach. La partida de Darío poco antes de la presentación pública del volumen II, coloca a este nuevo esfuerzo intelectual en el orden de un legado para los historiadores que hemos compartido con él la tarea de desentrañar los orígenes, desarrollo y significados del peronismo en las provincias y a escala nacional; fenómeno socio-político, que sin lugar a dudas, alteró la agenda de las Ciencias Sociales y de la historia en estos últimos sesenta ańos.

Es evidente que las sutiles observaciones de Macor y la mirada penetrante de Tcach permitieron que un conjunto de trabajos producidos por historiadores de distintas universidades del interior, fueran hilvanados para una puesta en común, en el marco de algunas intuiciones que los dos editores hicieron inteligibles en la introducción del primer volumen. «El enigma peronista» es un escrito que alimentó (y lo seguirá haciendo) numerosos debates desde su publicación hasta nuestros días. Allí los autores daban a conocer una 
nueva propuesta sobre las fases que habían atravesado las Ciencias Sociales, en general, y la Historia, en particular, con relación a las interpretaciones sobre el peronismo.

Los autores identifican tres fases en los estudios sobre el peronismo. La primera de ellas reúne a las interpretaciones definidas tradicionalmente como «ortodoxas» (producidas en la segunda mitad de la década de 1950), tributarias de las contribuciones sociológicas de Gino Germani ${ }^{1}$, caracterizadas por el análisis en torno a la falta de integración de los nuevos grupos sociales en un período de modernización de la Argentina. Con Torcuato Di Tella el fenómeno peronista queda vinculado a lo que el autor denomina "coaliciones populistas» ${ }^{2}$. La segunda fase corresponde a las interpretaciones «heterodoxas» (desarrolladas a partir de los '70), en torno a los aportes de Juan Carlos Portantiero y Miguel Murmis, y destaca el papel de los viejos sindicatos de la clase obrera y sus dirigentes tradicionales en la configuración de la alianza entre la clase obrera y la elite política que dio lugar al peronismo ${ }^{3}$.

A este esquema binario ya presente en otros estudios, los autores incorporaron un tercer tipo de interpretaciones, a las que denominaron «extracéntricas». Construida -afirman Macor y Tcach- por una «nueva generación de historiadores, que empezó a trabajar a partir de mediados de los ' $80 »^{4}$, esta fase se encargó de estudiar la génesis del peronismo en las provincias. En criterio de los autores, las interpretaciones «ortodoxas» $\mathrm{y}$ «heterodoxas» comparten tres elementos en común: provienen del campo de la sociología, centraron sus estudios en el caso de Buenos Aires y en los efectos del proceso de industrialización ${ }^{5}$. Por el contrario, señalan Macor y Tcach, las interpretaciones «extracéntricas» tienen como punto de partida un conjunto de interrogantes vinculados a explicar el surgimiento del peronismo en sociedades que presentan una débil industrialización, en las cuales, tampoco era posible apelar a las variables vinculadas a la presencia de los viejos y nuevos obreros surgidos de las migraciones del interior a los grandes centros industriales. Entonces, ¿cómo explicar las posibilidades de desarrollo del peronismo en el interior del país?

\footnotetext{
${ }^{1}$ Darío Macor y César Tcach, «El enigma peronista», en: D. Macor y C. Tcach (comps.), La invención del peronismo en el interior del país, vol. I, Santa Fe, Ediciones UNL, 2003, p. 9.

2 Ídem, p. 12.

3 Ídem, p. 17.

4 Ídem., p. 8.

5 Ídem., pp. 20-21.
} 
El conjunto de respuestas sobre la formación del peronismo en las provincias marcó, en general, otro rasgo significativo: el peso de las clases dominantes tradicionales desprendidas del radicalismo y aun de facciones conservadoras, frente a la debilidad de los sectores obreros para imponer ante Perón sus propios candidatos. Mientras que, en los territorios patagónicos, una sociedad civil débil y la ausencia de grupos dirigenciales con tradición política, parecía constituir al Estado en el principal promotor de la identidad peronista.

El papel del Estado, las clases e instituciones tradicionales, la escasa presencia del componente obrero industrial, en algunas casos más que en otros, marcaron el desarrollo del primer peronismo en las experiencias provinciales, dando una clave de lectura del fenómeno vinculada a cierta continuidad de antiguos actores que matizan y complejizan las perspectivas que conciben al peronismo como un "fenómeno único», diferenciado en el curso histórico por la irrupción del proletariado industrial. Al mismo tiempo que enfatizan la función articuladora del Estado, junto a los sectores patronales y la clase obrera emergente del proceso de industrialización de la década del '30.

Los trabajos reunidos en La invención del peronismo en el interior del país dan cuenta de la existencia de "partidos peronistas provinciales» que configuran una realidad que los autores denominan el "peronismo periférico». Ello implicaba el primer intento de escribir una nueva historia sobre el peronismo a través de un proceso inverso al que proponían las visiones «ortodoxas» $\mathrm{y}$ "heterodoxas», cuyos modelos explicativos se situaban en el estudio de los procesos centralizados en Buenos Aires, perspectiva que había predominado en el campo historiográfico y en las Ciencias Sociales.

En este punto quiero advertir que años antes a la publicación de La invención del Peronismo en el interior del pais, Mariano Plotkin, había producido en 1991 un artículo titulado: «Perón y el peronismo: un ensayo bibliográfico»", en el cual la versiones ortodoxas quedaban englobadas en lo que el autor denominó las «visiones patológicas» sobre el fenómeno peronista.

El ensayo también señala que, desde los años setenta, los trabajos de Portantiero y Murmis marcaron los primeros desarrollos de una versión alternativa a las «visiones patológicas», hasta llegar a los «estudios recientes que muestran una imagen del régimen peronista más rica y por lo tanto más compleja que la tradicional» ${ }^{7}$. Plotkin

\footnotetext{
${ }^{6}$ Mariano Ben Plotkin, «Perón y el peronismo: un ensayo bibliográfico», en: Estudios Interdisciplinarios de América Latina y el Caribe, Tel Aviv, vol. 2, № 1, 1991, pp. 113-135. Disponible en versión digital: http://www1.tau.ac.il/eial/index.php?option $=$ com_content\&task=view\&id $=691 \&$ ltemid $=263$

7 Darío Macor y César Tcach, «El enigma peronista», en: D. Macor y C. Tcach (comps.), op. cit., p. 16.
} 
se refería con eso a la complejidad temática y de abordajes de una historiografía que se renueva. No obstante, su ensayo bibliográfico sobre el peronismo siguió centrado en los trabajos a escala global sin dar cuenta de las producciones que comenzaban a indagar la complejidad de la formación del peronismo a través de las investigaciones sobre casos provinciales.

En los últimos años -desde el retorno a la democracia- los estudios sobre el peronismo se han multiplicado con los aportes de las producciones que realizan historiadores y científicos sociales en la constelación cada vez más numerosa de universidades, centros e institutos de investigación que han proliferado en todo el país. Los temas, los problemas, las preguntas también se han multiplicado al calor de los trabajos de becas, tesis de maestrías y doctorados. Asimismo, las publicaciones se han incrementado de manera significativa, por lo cual, los puntos de conflictos o confluencias de las interpretaciones siguen el mismo movimiento.

La conformación de redes de estudio, centros y jornadas académicas vinculados al peronismo, son un intento de congregar a todos aquellos que han constituido al primer peronismo o al peronismo en su conjunto en objeto de investigación. Las producciones lo indagan desde distintos ángulos convirtiéndolo, casi, en un campo de especialistas.

Un estudio publicado en el 2012 por Omar Acha y Nicolás Quiroga, El hecho maldito. Conversaciones para otra historia del peronismo ${ }^{8}$, ofrece algunos elementos más para pensar los aportes iníciales de La invención del peronismo en el interior del país y puede dar pistas de los efectos que puede producir la aparición y circulación del segundo volumen que cuenta con una introducción, «El oxímoron peronista en las provincias»" ${ }^{9}$, texto cuya defensa Darío Macor colocó en la alforja que cae sobre las espaldas de Tcach.

El título desde ya invita a pensar que Macor y Tcach redoblan la apuesta utilizando otra figura retórica. La primera, recordemos, fue el «enigma» usado con astucia y lucidez por los autores, para develar al peronismo en su formidable estructura de poder de clase revestida de consenso obrero. Ahora, Macor y Tcach utilizan la figura del «oxímoron» que evoca la presencia de dos conceptos o sentidos contrarios que podría encerrar el «enigma peronista»: fortaleza y debilidad, ampliación de la ciudadanía política y social,

\footnotetext{
${ }^{8}$ Omar Acha y Nicolás Quiroga, El hecho maldito. Conversaciones para otra historia del peronismo, Prohistoria Ediciones, Rosario, 2012.

9 Darío Macor y César Tcach, «El oxímoron peronista en las provincias», en D. Macor y C. Tcach (comps.), La invención del peronismo en el interior del país II, Santa Fe, Ediciones UNL, 2013.
} 
democracia y apelación a la coerción y al disciplinamiento, es decir, autoritarismo, junto a otros dos valores que fluctúan en el desarrollo del peronismo: lealtad y traición.

Es decir, en cierto sentido, siempre la dicotomía parece establecer el ser y no ser del peronismo, cuando quizás, la identidad peronista subsume lo dicotómico y allí podría estar el punto central del problema que atraviesan las investigaciones reunidas en el volumen II de La Invención del Peronismo en el interior del pais. Pero antes de avanzar, quisiera retomar el libro de Acha y Quiroga, muy interesante en su formulación inicial presentada a través de una amena conversación entre los autores, estrategia discursiva utilizada para revisar los aportes e interpretaciones sobre el peronismo y para pensar «otra historia del peronismo».

Los autores recuerdan aquella aseveración de Luis A. Romero acerca de la «etapa de normalización» en que parecen haber entrado los estudios sobre el peronismo, dejando atrás las consideraciones en torno a las cuales el peronismo configuraba un «hecho compacto y excepcional», posición a la que contribuyeron -dirá Romero- tanto, defensores como detractores de un fenómeno político que obligaba a la toma de posición en su momento. Con lo cual pensaba que la «valoración global retrocede ante la necesidad de comprender una realidad compleja» -y afirma Romero- «Empieza a distinguirse en el peronismo un conjunto de historias, diversas y confluyentes, cada una con una especificidad que requiere alguna sapiencia especial ${ }^{10}$.

En alguna de las afirmaciones que desbroza el texto de Romero, Acha y Quiroga creen descubrir las raíces «socialdemocratizante» $y$ «evolucionistas» de la normalización evocada por el autor, compatible con el contexto de producción de los años ochenta (transición democrática) y el retorno a un "país normal» frente a la violencia del periodo anterior ${ }^{11}$.

Para Acha y Quiroga, el programa de normalización historiográfica abierto en los ochenta, sin embargo, tiene en Germani un "padre primordial», deriva intelectual que podría estar presente en el caso de La invención del peronismo en el interior del país I, texto que contiene una serie de afirmaciones que si bien ellos podían compartir, más les interesa debatir el «lugar de lo patológico» en la producción de los historiadores que forman parte de la publicación.

Acha y Quiroga, tienen la presunción que, si bien lo patológico no forma parte del objeto de investigación de los autores antes mencionados, es posible descubrir que la

10 Luis A. Romero, «Relectura de una época», en: La Nación, 30/04/2005.

${ }^{11}$ Omar Acha y Nicolás Quiroga, op. cit., pp. 21-25. 
noción de "conflicto» tributa a un enfoque sociológico que se detiene en la evolución de la ciudadanía y se inscribe «bajo presupuestos políticos democráticos-liberales» ${ }^{12}$, propia del contexto de producción historiográfica de la transición democrática. Los autores van desenvolviendo su propuesta a lo largo de los artículos que componen el libro, señalando que consideran importante asumir la tarea de desublimar la «normalidad historiográfica», para pensar críticamente el «disciplinamiento científico de la historiografía» tal como se la viene practicando en los dos últimos siglos «bajo el tenor de la narrativa realista» ${ }^{13}$.

La invención del peronismo -sostienen- contiene varias confirmaciones compatibles con los objetivos de sus editores, una de ellas, que el peronismo está integrado por partidos y sectores «tradicionales», y que es un partido de Estado que estuvo atravesado de conflictos. En otro apartado plantean que la compilación, es una buena fotografía de lo que comenzaba a hacerse en el campo de la historia política: «poca teoría, mucho archivo y en esos archivos, mucha prensa ${ }^{14}$. Señalando que, si bien la compilación atiende a los conflictos, los autores no parecen preocupados por profundizar el estudio del partido Peronista en sí. Estudios que, finalmente, van a provenir desde el campo de la Sociología, con Moria Mackinnon y su libro Los años formativos del partido peronista, mostrando la conjunción de «mucha teoría, más archivo», aunque denota una presencia significativa el «modelo de partido» propuesto por Ángelo Panebianco.

Ante el presente estado de la cuestión -que los autores desarrollan meticulosamente y supera la posibilidad de síntesis para este breve artículo-, van a considerar como más pertinentes, para una historia política del peronismo, las contribuciones de una historia social de la cultura en diálogo con la política. Citando, entre otros, los aportes ya analizados de Mariano Plotkin, los de Fernando Balbi sobre el lugar de la «lealtad» en el repertorio peronista o los trabajos de Mariana Garzón Rogé sobre el concepto de perfomance cuando indaga las formas de legitimación de un Interventor peronista en Mendoza $^{15}$. Acha y Quiroga a pie de página aclaran que saben que este trabajo forma parte del segundo tomo de la Invención del peronismo en el interior del país, que se encontraba en prensa ${ }^{16}$. En tanto anuncian la llegada de una «nueva historia cultural del peronismo» o una "historia cultural de la Argentina peronista».

\footnotetext{
12 Ídem., p. 36.

13 Ídem., p. 38.

14 Ídem., pp. 85-86.

15 Ídem., p. 108.

16 Ibíd.
} 
Las referencias realizadas sobre las críticas y los aportes que recibió La invención del peronismo en el interior del país, también tienen que ver -me parece- con otra cuestión relacionada, en parte, a las estrategias de los historiadores en la construcción de un sub-campo académico atravesado por las disputas de saberes que se producen dentro de él y que están vinculadas, sin lugar a dudas, al control de los espacios, los recursos, el prestigio académico y los posicionamientos políticos enlazados al curso actual del desarrollo histórico en la Argentina. Receptado el aporte crítico de Acha y Quiroga en una de las alforjas del hombre de la fábula de Esopo, veamos qué otros elementos analíticos pueden contener las alforjas.

Resulta llamativo que distintos trabajos (un número de once en el primer volumen y dieciséis en el segundo) realizados por investigadores de distintas Universidades, con escasa relación entre sí, pudieran coincidir en el desarrollo de sus investigaciones en algunas apreciaciones compartidas y puestas en evidencia por los editores de La Invención del peronismo en el interior del país. ¿A qué se debía este hecho? ¿Efectos de una moda historiográfica? ¿Oportuna mirada analítica de Macor y Tcach para seleccionar aquellos trabajos que corroboran algunas de sus afirmaciones? ¿Intuiciones y reflexiones emergentes de la indagación de las fuentes disponibles?

Lo cierto, es que la mayoría de los investigadores de provincia deben haber realizado sus investigaciones casi sin contar con trabajos académicos locales que sirvan como antecedentes, además de afrontar la falta de archivos partidarios o, como el caso de Salta, documentación fragmentada en los archivos de los juzgados electorales (nacionales y provinciales), desmantelados por distintas circunstancias, entre ellas, por la acción represiva de las sucesivas dictaduras militares o la carencia de una política de resguardo documental. En nuestro caso, la primera tarea que tuvimos, fue la de tratar de evitar que se siguieran perdiendo las escasas fuentes y la posibilidad de recopilar los testimonios orales de quienes todavía podían brindar información del primer peronismo. De hecho muchos de quienes nos dieron sus testimonios en el curso de las investigaciones realizadas en los años noventa, han fallecido.

En forma simultánea, el grupo de investigadores multiplicaba sus esfuerzos en el relevamiento de expedientes, informes, memorias de funcionarios y organismos oficiales, fuentes estadísticas sobre población, producción, circulación, formas de propiedad de la tierra, formación del mercado laboral, reuniendo todos los elementos posibles, tendientes a establecer la distribución de las fuerzas productivas y caracterizar la estructura socioeconómica de la provincia y en algunos casos, de la región. Al mismo tiempo profundizamos en el caso de Salta, el estudio crítico de las fuentes periodís- 
ticas con el objetivo de conocer en profundidad los aportes y limitaciones que éstas podían ofrecer a la investigación del primer peronismo, en un contexto de profundos enfrentamientos y divisiones ${ }^{17}$.

Sin lugar a dudas, la prensa fue y sigue siendo una fuente importante para comprender algunas representaciones y prácticas sociales que conforman la compleja dimensión de la cultura política provincial. Estos esfuerzos, también abrirían el campo a nuevas indagaciones sobre las características del Estado provincial y las acciones desplegadas en el escenario local por los actores sociales y políticos que íbamos identificando a la luz de los eventos que captaban el interés del discurso periodístico.

Los equipos de investigación, en nuestro caso, estaban compuestos por docentesinvestigadores de «vieja escuela»; otros, con formación académica reciente. Unos con más experiencia en el campo de la historia política, otros vinculados a los trabajos provenientes del materialismo histórico en torno a las relaciones de producción predominantes en la provincia. Los trabajos en equipo fueron el resultado de una transacción en torno al desarrollo de una historia social de la política y un esfuerzo por conceptualizar los sujetos que accionaban en un espacio concreto de relaciones sociales de producción y un campo de disputa en torno al Estado provincial. Un registro fuerte fue, sin lugar a dudas, ciertas limitaciones estructurales emergentes de la marginalidad provinciana con relación a los principales centros productivos y políticos del país ${ }^{18}$.

Los distintos trabajos encarados por el equipo de investigación muestran, por un lado, las tensiones en la estructura de clases, las concepciones y organizaciones previas que deberán desmontarse paulatinamente desde el Estado, para organizar el partido peronista concebido como una estructura vertical con penetración molecular en la sociedad

\footnotetext{
${ }^{17}$ Rubén Correa y Marta Pérez (coords.), Intelectuales, política y conflictividad social en Salta durante la década del veinte. Estudios desde la prensa escrita, Salta, Ed. Milor, 2008.

18 Dos trabajos previos, aunque publicados casi al mismo tiempo que aparecía La invención del peronismo en el interior del país, constituyen la base del artículo que aparece en el primer volumen. Me refiero a las publicaciones de la Revista Historia, № 2, año 2003, «Tendencias en la formación económico-social salteña durante el primer peronismo, 1946-1951» y en Revista Historia, № 3, año 2004, «Conflictos, alianzas sociales y etapas en el proceso de formación del peronismo salteño entre 1946-1949». En este último ya estaban planteadas las líneas directrices sobre una historia de las distintas fases que abarcó la construcción de una estructura partidaria peronista, trabajo definitivo que está incorporado al segundo tomo de La invención del peronismo en el interior del país, en el capítulo que lleva como título: «Las agencias del poder: intervenciones partidarias y formación del partido peronista en Salta, 1949-1952».
} 
a través de las unidades básicas ordinarias (políticas) y las gremiales. El reemplazo de las estructuras de comités y convenciones de tradición radical/conservadora en la provincia y la disolución del Partido Laborista, no fueron sencillas. Implicaron negociaciones, luchas frontales y rupturas que arrastraron a la provincia a distintas intervenciones federales y a una intervención permanente del Partido Peronista. El estudio se detiene en el análisis del papel del Partido Peronista Femenino en la provincia de Salta hasta la muerte de Eva y su posterior disolución, quedando en este tema todo por hacer.

Las claves interpretativas de este proceso residen en dos conceptos que constituyen el hilo conductor de la investigación, uno de ellos, pone énfasis en los esfuerzos por construir, desde el Estado, un liderazgo al que caracterizamos como «cesarista corporativo» legitimado en procedimientos de una "democracia plebiscitaria». En uno y otro caso, compatible con el ideal de "comunidad organizada» y la necesidad de controlar todo tipo de disidencia. Allí es donde el partido juega un rol central como agencia de las políticas del Estado de compromiso y control social que impone Perón desde el poder.

\section{A manera de conclusión}

Es evidente que si las condiciones de producción en cada momento histórico han marcado el desarrollo de la historia de la historiografía argentina, la sociedad polarizada del primer peronismo dio lugar a los estudios que encuadramos en las interpretaciones historiográficas «ortodoxas». En tanto, las versiones «heterodoxas» buscaban dilucidar el papel de la clase obrera en un momento donde algunos intelectuales de la «nueva izquierda» intentaban enlazar su proyecto socialista en el cuerpo del único movimiento de masas con capacidad de llegar al poder.

En los ochenta el retorno a la democracia marcó la primacía de la política frente a la violencia. Durante la década de los noventa, el triunfo de Menem y las políticas de ajuste estructural del Estado, están en la base de las preocupaciones del ensayo bibliográfico que analizamos en líneas anteriores e intentan dar cuenta de la naturaleza distinta y contradictoria que conforma al peronismo. En la Invención del peronismo en el interior del país I y II, está presente un amplio registro de lo diverso y paradójico que resulta el fenómeno peronista en un espacio nacional.

Sin duda alguna, el peronismo es un fenómeno que interpela permanentemente a los intelectuales. En este sentido Omar Acha y Nicolás Quiroga tienen razón cuando afirman que «el kirchnerismo y los conflictos políticos y sociales que tienen lugar en la actualidad nos han puesto a interpretar papeles y nos hemos visto a nosotros mis- 
mos diciendo cosas parecidas a las que otros intelectuales dijeron frente al Perón de la Secretaría de Trabajo y Previsión o frente al Perón del exilio» ${ }^{19}$.

Puestos en este contexto, al historiador como a muchos otros intelectuales ¿̨le será posible conceptualizar el fenómeno del peronismo por fuera de un escenario político concreto sobre el cual se despliegan sus propias prácticas como historiadores? El historiador con oficio conoce bien la respuesta y sabe los desafíos que implican la producción de conocimiento histórico y los debates que pueden producirse en el campo académico, más aún en coyunturas políticas de crisis.

Está claro que las dos alforjas que colgó Prometeo al hombro de Esopo están sobre los hombros de los historiadores. Habrá que ver si es posible cambiar la posición de aquella alforja que guarda hacia adelante los defectos ajenos, con relación a la otra que va atrás y lleva los defectos propios. Finalmente, es importante ratificar que el «momento democrático» difícil y contradictorio por el cual atravesamos, sigue siendo un campo propicio para condensar los aportes de los numerosos estudios sobre el peronismo en un fructífero intercambio de perspectivas históricas.

19 Omar Acha y Nicolás Quiroga, op. cit., p. 11. 